\title{
A Study on the Translator's Subjectivity
}

\author{
-An Analysis of English Version of Song of the Burial of Flowers \\ Tang Lin \\ Weinan Normal University College of Foreign Language, Shannxi, Weinan, 714099
}

Keywords: translator’s subjectivity; English version; Song of the Burial of Flowers; Lin Daiyu

\begin{abstract}
Translator serves as the conductor in the process of translation. The translator's subjectivity, an objectivity existence in the process of translation, has a direct impact on the process and the result of translation. In literary translation, the translator renders the original text. Though limited by ideology, peotics and the translation agency, the translator's subjectivity still works. To correctly and fully bring the translator's subjective initiative into play is the key to success. With the culture turn uprising in 1970s, the once marginalized position of the translator now draws theorists' attention. The study of translator's subjectivity has aroused a heated debate among Sino-foreign scholars.
\end{abstract}

This thesis aims to study translator's subjectivity, taking the English version of Song of the Burial of Flowers as an example. And it includes an introduction, embodiment of translators' subjectivity in the English version of Song of the Burial of Flowers, factors affecting the translators in translation based on the English version of Song of The Burial of Flowers and the translation standard guiding translators in translating. Results of the discussion are used to summarize how translator's subjectivity works in the translation of Song of the Burial of Flowers.

\section{Introduction}

There isn't really a definition of translator's subjectivity. Everyone has his or her preferences. Some think that translator's subjectivity is the exterior subjectivity of a translator in the process of translation in order to achieve a certain purpose. Others hold the view that it refers to the subjectivity in the process of translation in order to achieve his or her purpose according to the original context. Or it's the way a translator creatively brings his or her subjective and unique initiative into play. The conscious sense of cultures, character of humanism and creativity of culture and aesthetics compose of its basic features.

The subject differs from subjectivity. The later is a matter of philosophy. "Subjectivity is a central philosophical concept about consciousness, agency, personhood, reality and truth, which has been variously defined by sources. Three common definitions include that subjectivity is the quality or condition of:"Something being a subject, narrowly meaning an individual who possesses conscious experiences, such as perspectives, feelings, beliefs, and desires; Something being a subject, broadly meaning an entity that has agency, meaning that it acts upon or wields power over some other entity (an object);Some information, idea, situation, or physical thing considered true only from the perspective of a subject or subject."( Solomen 900).

According to Bing Dictionary, subjectivity means: "Interpretation based on personal opinions or feelings rather than on external facts or evidence; Concentration on personal, individual responses in artistic expression.” (Bart 367).

These definitions are sometimes a matter of philosophy. The issue is most commonly used as an explanation which influences, informs, and biases people's judgments about truth or reality; it is the combination of the perceptions, experiences, expectations, personal or cultural comprehension, and beliefs especially of a person. Usually it is used in contrast to the issue objectivity as a view of truth or reality free from any sort of influence.

Translators conduct the process of translation. They are the first readers of the original texts. This 
reading process matters in creating the translation version. Translators are supposed to leave enough space for readers to imagine. Theoretically translators' role functions as well as the writer. Translation is another type of writing. It is supposed to inspire the readers rather than limit them. Different readers have different opinions on translation. Opinions varies in different times and circumstances. Different translators create different translation versions.

The past years has seen the development of translation theories on the importance of translators' subjectivity.

According to Polysystem Theory,” the position of translation literature affects translation standards, behaviour models and translation methods" (Shuttleworth 201). The Structuralist Theory explains the construction and meaning of words in the way of new philology. According to this theory, the deconstruction value believes that translators are creators and sees the translation version as the new-born creation of language (Ferdinand 245). The Manipulation Theory is offered by Bassnett. He held that translation is not a pure language behaviour Instead, it comes from culture. "Translation is the communication between inner cultures" (Bavelas 328). The Translation Psychology Theory holds that translation in which language is the process of transformation is a psychological process of thinking and imagination once the translators get language signals." (Fernald 208).

Traditional translation studies tend to emphasize the original text, neglecting the translators. Translation theorists drew attention on the nature, criteria and techniques as if translators didn't matter. Indeed, translators' role can be limited. Yet translators do decide the final translation version. To be a translator, one has to be both a writer and linguistic. The studies then took an unexpected turn in 1970s: the cultural turn. Since then, attention has been drawn on translator's subjectivity which studies the translator himself or herself.

Recent years in Chinese translation circle, research on translators' subjectivity has been popular. Attention has been drawn to the embodiment and importance of translator's subjectivity and how to take it into practice. During the process of translation, translators are the principle part for they are not only the conductor of translation, but also carry the individualities which are independent from other objects. Translators as the main part of translation process embody their subjectivity, motility and creativity when translating in order to reach translation purposes.

There are two schools in the modern translation field. One focuses on the translation products, doing research on translation strategies, the comprehension level of the original and target culture, the limitations of subjectivity say translators' nation, class and political background. The other focuses on the process of translation which contains the thinking activities of the brain.

Studies has grown rapidly in the 1990s with the development of the "thinking aloud method" which belongs to the self-thinking method in data collection of thinking process, to put it another way, to store the subjects spoken out in mind while doing tasks. (Lewis 1982).

There are two views in the translation circle on whether "thinking aloud method" is suitable to be applied to the research of translation process. One holds the view that if the human thinking process is taken as an information transferring process instead of a pure activity in a complicated system, "thinking aloud protocols" can reflect the thinking process and is the most natural and most suitable way of studies on the translators' thinking process. The other holds that "thinking aloud protocols" can only reflect thinking process in an indirect way. Thus translators' subjectivity is mixed with the data analysis. Additionally, the influence caused by different translation models of translation and interpretation to the process of translation isn't clear, thus limited the studies on "thinking aloud method".

In all, the cognition of translators' subjectivity has gradually transferred from the exertion of their subjectivities to the direct research of translators' thinking activities. So far, most attention has been drawn on the study of the translation of the song among the other songs in the fiction.

\section{Embodiment of Translator's Subjectivity in the English Version of Song of the Burial of Flowers}

In this thesis we will take the version of Yang Xianyi and Dai Naidie as an example. 
Translators Yang Xianyi and Dai Naidie has started to translate the fictions since 1960s.They once stop but manage to accomplish it in 1974. The book, A Dream of Red Mansions, is divided into three parts and published from 1978 to 1980.It is widely write-up over the world.

A native translator does have an advantage in the comprehension of the original text. Compared to modern works, the translation of songs and poems asks for higher competence in accuracy.

Yang Xianyi is a Chinese literary translator, known for rendering many ancient and a few modern Chinese classics into English, including Dream of the Red Mansion.

Yang is born in Tianjin. His parents are wealthy bankers and offer him good education. He goes to Merton College and then gets into Oxford. There this classical literature major marries the first Chinese literature major Dai Naidie. The couple have three kids: two daughters and a son who commits suicide in 1979

When he is a little boy, he goes through a lot of sino-foreign classics. In middle school, he begins to read original English books like works of William Shakespeare and write poems and chapters (a type of traditional Chinese novels with captions for each chapter) using parallelism.In high school he completes over 100 poems. Unfortunately, most of them are lost. Later he gets into an English catholic school, during which he translates epics from Homer to Longfellow. Eventually he graduates as the master of Classical Literature of Oxford and could master a few languages. He loves drinking and collecting calligraphy, paintings and books. All these make him a walking dictionary.

This was no coincidence. Yang's father is once an amateur classical poet. His son Yang is born with a sensitivity in languages and arts and well educated.

Yang and his wife go to China in 1940, and begin their years long cooperation of rendering Chinese classics to the English-speaking field. Working for the Foreign Languages Press in Beijing, a government-funded publisher, the husband and wife team produces a lot of qualified translations. The translated works include classical Chinese poetry; classic works as Dream of the Red Mansion, The Scholars, Liu E's Mr. Decadent: Notes Taken in an Outing, also known as The Travels of Lao Can, and some of Lu Xun's stories.

Yang is also the first one to translate the Odyssey into Chinese from the ancient Greek original. $\mathrm{He}$ renders Aristophanes's Ornites, Virgil's Georgics, La chanson de Roland and Bernard Shaw's Pygmalion into Chinese and is noted for writing doggerels. His autobiography White Tiger is published in 2003.

He finally escapes being labeled a rightist in 1957 to 1958 for his frank speaking. However, Yang and his wife Dai are imprisoned for seven years as class enemies in 1964 during the Cultural Revolution.

Dai Naidie is a British translator. Her father is a missionary to China and, since childhood, she has become a fan of Chinese culture.

Gladys Margaret Tayler is her full name. Born in Beijing, she returns to England as a child and becomes Oxford's first graduate in Chinese Literature in 1940. After her marriage, the Beijing-based couple become prominent translators of Chinese literature into English during the latter half of the twentieth century.

At school she gets straight as and received a scholarship to Oxford. She is the first Chinese Literature major who gets the Honours Degree. E.R. Hughes is her tutor. She learns the excerpts of the Confucian like The Book of Songs and The Analects of Confucius. Yang advises her to read some Chinese classical poems and mythical stories. In 1940s she goes to China with Yang, she is able to write Chinese in regular script and stories with old Chinese. She doesn't come to China for revolution, she comes for her love for Yang, the memories of her childhood in Beijing, and her admiration for Chinese culture. She is in love with A Dream of Red Mansions. Furthermore, she holds the view that the last 40 chapters almost destroy the fiction.

During the Cultural Revolution, the couple are imprisoned. Later they speak out against the 1989 Tiananmen Square massacre. As a result, their biography has been officially banned in China. Dai dies in Beijing in 1999, ages 80.

Translation is a demanding profession. Yang has the privilege of living in the country in which 
the source or target language is spoken. Together Yang and Dai acquire bilingual competence. The translation of a text by a team of translators is generally a quite different process and involves very different procedures. During the process of translation, Yang first translates the fiction and Dai is supposed to edit it. It takes Dai a lot of time to update it. She is praised for her hard work.

With Yang's knowledge of Chinese language, they adopts the method of foreignization. Thus they records actual events, reserves the original meaning and foreignizes the fiction. So the exotic features and traditional Chinese culture in the fiction are reserved and promoted.

In dealing with rhythms, they adopts "abcb” model, making it fluent and natural like the original text. It's like a four-line poems with seven characters to a line and a strict tonal pattern and rhyme scheme.

At the same time, Dai a native English speaker helps bring the translation to the next level.

They prefers literal translation than free translation, which helps in translating the lyrical song.

“花谢花飞飞满天,红绡香断有谁怜。”

"As blossoms fade and fly across the sky,

Who pities the faded red, the scent that has been?"

They use verbs "fly, pity and float" to convey the image of the flowers and artistic conception of the burial. Readers can feel the sense of sorrow in the prospect.

“明媚鲜妍能几时? ”

"How long can beautiful flower fresh and fair?”

The word flower is direct and clear.

“一朝春尽红颜老”

"The day that spring takes wing and beauty fades"

Beauty stands for Lin Daiyu.

In the song, Yang selects iambic in the beginning.

“游丝软系飘春榭, 落絮轻沾扑秀帘”

"Softly the gossamer floats over spring pavilions,

Gently the willow fluff wafts to the embroidered screen."

The first and second sentence parallel with each other neatly. The two adverbs "softly" and "gently" in the beginning make people imagine the way gossamer falls. And the two verbs "floats" and "wafts" emphasizes the mood. Note that they adopted "spring pavilions". It refers to a wooden house on a terrace or beyond the water.In Old China, these sorts aren't built for living but for entertainment. According to the background, Lin Daiyu buries the flowers near a rockery or a creek.

Bilingual transformation competence is not the only criteria. At the same time a competent translator is supposed to have cultural transformation competence. A language is not simply a mixture of words, rules of grammar and syntax for generating sentences, but also a grand interconnecting system of connotations and cultural references whose mastery, writes linguist Mario Pei, "comes close to being a lifetime job." (Mario 76) A translator must be able to sense what is purposely left implicit in the source text and what can and should be made explicit in the translated text. Biculturalism is something which must be absorbed in a living situation.

There are thousands of translators in the world. Only the best can make to the top. One has to learn both languages and cultures. After this he or she may need at least ten years to practice. Thus it is wrong to say that a person who has mastered two languages will, absolutely be competent to be a translator.

“酒上空枝见血痕。”

"Falling like drops of blood on each bare bough.”

He is trying to remain the original cultural image in the fiction. This comes from the literary quotation Princess Xiang Cries for Shun (the name of a legendary monarch in ancient China). She cries and bleeds until the blood dyes the trees. Lin Daiyu has a sobriquet as princess Xiaoxiang which refers to princess Xiang. By the legend the writer expresses his sorrow. 


\section{Factors Affecting Translators in Translation}

Among the factors in translator's subjectivity there are two types: personal and social factors. The former composed of translator's bilingual and intercultural competence, translator's personality, etc. The latter involves ideology, poetology, power, etc., which controls translators.

When Yang is studying in Oxford, he has never thought of becoming a translator. He prefers history. Although he once translates The Lament into English using heroic couplet. All he wants to do is to show off the long-standing Chinese literature tradition to the British teachers. It is just for fun. If he had a second chance, he would research after old Chinese history. He finally accepts the invitation of Department of Translation and Edition for Dai's sake. It is then that they found together they stand out for they have the advantage of complementary. Eventually Yang becomes a translator by chance. Personally, he isn't interested in A Dream of Red Mansions. But he doesn't have a choice. As a translator in Foreign Languages Press, he has to do what he is asked. So does Dai. As he says later: "The truth is I don't really like A Dream of Red Mansions that much. Those people and those things are much alike my old family. I'm not interested.” (Yang 18) But there isn't any proof that he is demanded to translate in a certain way by the press.

He himself is a Jia Baoyu. As a pupil he is intelligent but lazy, even a bit rebellious. He doesn't have to work hard to get the first place. But his grades rank second all the time. Although he has gone through a great deal of sino-foreign masterpieces, he hasn't finished reading A Dream of Red Mansions until he is asked to translate it.

Translation is not easy. Literary translation is even harder. Translation is not a simple transformation of words and sentences. Multi-dimensional contrastive studies of English and Chinese are very important for a translator to develop his or her interlingual awareness of the different features between the two languages. Based on different academic background, different translators deliver different translation versions.

There are several manuscripts of the original fiction. Living in China, they have advantages. The Redologist Wu Shichang selects the best one for them.

By the time he is working on the translation in 1950s to 1960s, great leap forward which called for efficiency was going on. For instance, A Brief History of Chinese History written by Lu Xun is translated in a week. In translation we see the truth of the translator instead of the writer.

Pressed for time, they have no choice but to interpret it. Yang interprets it. At the same time Dai types. Some may hold the view that this interpretation isn’t any good for a professional translator. Yet to some extent in this way it helps the translator directly expresses the feelings of the characters. Here I will cite the use of persons and tenses as instances.

Persons and tenses have an impact on the view and moods of a translation. In Yang's version, he uses the third person in the former and the first person the later part. That is to say, in the second, the third, the sixth, the seventh, and the thirteenth stanza he uses the third person. And in the middle say the eighth, the twelfth and the eighteenth stanza he uses the first person. The original context is considered. Using the third person shows the activities of the heroine. And the first person helps to express Lin Daiyu's true feelings. One problem is that Yang switches a lot. Frequent change of perspectives can get into trouble. Also, he frequently changes tenses like the simple present tense, the simple past tense and the simple future tense. The simple present tense appears from the first stanza to the seventh stanza.

The last stanza is the most difficult one. Yang uses simple present tense to make it natural and objective. For the last two sentences, Yang adopts the simple present tense to the clause and the simple future tense to the main clause. He also transfers the original exclamation into rhetorical question, leaving the space for readers to think about the fate of the poet Lin Daiyu.

“杜鹃无语正黄昏”

"Dusk falls and the cuckoo is silent;"

Why is cuckoo silent? It has been crying and bleeding. In spring and summer, cuckoo rings clearly and shortly day and night. Its red mouth and tongue make Chinese ancients think that it rings until it bleeds. That's why cuckoo is considered a sad and mysterious bird. Chinese men of letters 
see it as the sign of sorrow. For example, in the legend the King of Shu Wangdi becomes a cuckoo after his death. The king loves his people. Even after his death his ghost still cares about the people and their agriculture. He becomes a cuckoo. In Tomb Sweeping Day, Grain Rain, the beginning of summer and Grain Full, he flies to the fields and rings. Hearing the ringing, farmers understand that it is time for sowing. On the other side, cuckoos stand for happiness in English.

For instance,

"Even yet thou art to me no bird, but an invisible thing, a voice, a mystery; The same whom in my schoolboy days I listened to; That cry which made me look a thousand ways. In bush, and tree, and sky. To seek thee did I often rove. Through woods and on the green; And thou wert still a hope, a love; Still longed for, never seen. And I can listen to thee yet; Can lie upon the plain and listen, till I do beget that golden time again. O blessed bird! The earth we pace again appears to be an unsubstancial, faery place; That is fit home for thee!"

(To The Cuckoo by William Wordsworth,1770-1850)

You see, the cuckoo represents "a mystery", “a hope","a love” and "an unsubstancial faery place”. Yang's version comes out quickly but there remain a lot to think about.

Yang loves freedom.But the couple is guided by the press. Yang and Dai don't have a choice but to do the translation. As they say:” A lot of foreign friends don't understand us.” (Yang 117) The truth is they are asked to do it by Foreign Languages Press introducing the Chinese classical culture to the outside world. Obviously, their translation is more of enlightenment than aesthetics. On the other hand, this English translation isn't translated to native English speakers. From the establishment of People's Republic of China to the middle of 1970s, most of our diplomatic friends are socialist countries from Asia, Africa and Latin America. Thus the communication between Chinese literature and the Asian, African and Latin American literature is hot. As Yang has said when interviewed by the journalist" ... In all we had over 100 famous Chinese classical literature works published. It was good. We translated some of them and put out some pamphlets. Some were published in Chinese Literature over the world at about 10,000 per issue. Most of the readers are from Pakistan and India. Some are American. In Britain it isn't that marketable.” (Yang 86) The readers are supposed to be the brothers and sisters from Asia, Africa and Latin America. Their translation is on the one hand a cultural exports from a powerful culture to a weak one, on the other hand a weak nation with a strong culture to a strong nation with a strong culture. How could they express this complexity? They are like the 72 men who translated the Bible. Those men had to center on the original works and the writer with the guidance of the god. The couple is guided by the Foreign Languages Press. This is why the national ideology is kept.

\section{The Translation Evaluation Guiding Translators in Translating Faithfulness}

Faithfulness means the translator is faithful to the original text. He or she is supposed to correctly and fully convey the original meaning. Any phenomenon of sophisication, misrepresentation or loss of the original text is forbidden. A translator must have an excellent command of both source and target languages to ensure that his or her comprehension is accurate and his or her renderings are smooth and faithful to the original context. The original native style, age style and the writing style should be reserved. The translator should not rewrite with his or her own language style. For instance, informal oral languages should not be rendered as formal languages. Vulgar words shouldn't be expressed as graceful ones. Western texts shouldn't be rendered as Orient works. The translator is supposed to reserve the original spirit as much as he or she can. Faithfulness is the very first criteria in translation.

There is a view held by traditional translation theorists that translators should avoid the act of creation. That is to say, translation is a kind of imitation and translation version relies on the original version so that it lacks creativity. On the one hand, the traditional translation value considers 
translation to be lack of creativity and cannot match the original one; on the other hand, the subjectivity and creativity of translators are objected. Translators are supposed to be faithful to the original authors, the original text and reject creative action in the translation version without analyses.

It is difficult enough to the original, and yet if a translation is not expressive, it is a tantamount to having no translation. Hence expressiveness should be required too. Translators need to have special aptitudes for clear and pleasing verbal expression. A careful translator should weigh the meaning of the original before choosing suitable words. Confucius says that expressiveness is all that matters in language. Expressiveness, that is to say the translation version must meet standard and be easily understood. The language is supposed to be standard modern language. He or she who translates should avoid verbatim and stilted translation. Languages used should be easy to understand and logical. During the process of translation, the translator should try his best to make his words understandable. Expressiveness cannot exist without faithfulness. Loss of either element may cause difficulty in readers' comprehension. Apart from the faithfulness of the original text and style, expressiveness loses its function, making the translation version a fable. Good expressions should be grammatically correct, rhetorically sound, logically acceptable, and culturally appropriate.

To achieve faithfulness and expressiveness, the translator is supposed to have deep comprehension of the original context. Either deep comprehension or correct expression is hard to achieve. To reach the criteria demands for knowledge and practice.

Elegance asks for the responsibility of art transformation. Beautiful languages help bringing the translation to the next level. Elegance can be achieved in rhetoric, style, rhyme, peotology and psychology. This criteria demands the translators' aesthetic competence. Confucius says that if one's language lacks grace, it won't go far. “I also aim at elegance. I strive for elegance not just to make my translations travel far, but to express the original writer's ideas better, for I find that subtle thoughts are better expressed in the vocabulary and syntax of pre-Han prose than those of the vulgar writings of today.” (Yan Fu 189)

Tanslators' role can be limited in the process of translation. His or her subjectivity relies on ideology, the study of poems and the patron. Literature is like a further creation. The aesthetic competence of a translator helps to make the reading enjoyable. Speaking of aesthetics, subjectivity plays a big role.

In all, there are many ideal standards in the traditional translation field. Translation has to do three difficult things: to be faithful, to be expressive and elegant. These three qualities, then are the criteria of good writing. And of good translation too. Yan Fu puts forward this "Three-character Guide" in his preface to the translation of T.H. Huxley's book Evolution and Ethics and Other Essays. Another famous translation theory is "transmigration theory" by Qian Zhongshu. The "transmigration theory" is also called "invisibility of translator" by western translators. The criteria of translation function both as the guiding principles for the translation process and as the standards for determining the quality of the translated works. The original text consists of two constituent ingredients: content and form. Translation criteria generally involve of these aspects. Well-known translators or translation theorists at home and abroad have put forward criteria to judge the quality of a translation. The ideal translation versions should be clear enough to convey the original meaning automatically without readers' feelings of reading translation version. However, either "transmigration theory" or "invisibility of translator" is tough to get. These three elements exists together in a delicate balance. The translator is supposed to understand that balance.

\section{Conclusion}

Translation has a long history. Translators are described as match maker, traitor, translation machine, cultural carrier etc.In these we see the traditional translation value: translation in the changing process between interlinguistics and studies on translation is to explore how to translate and achieve the best effect. If translation is taken as the transformation across linguistic levels, then translators deserve the appellation of language technological workers and cultural tools. 
There is no doubt that translation is a great contribution to the Chinese cultural development. Translators create the translation version and promote the culture. However, translators aren't respected like the original writers. In China, writers deserve a high social level. Popular writers like Guo Jingming, Hanhan and Rao Xueman make a lot of money. In China, the writer's and the editor's name is listed before the translator in a book cover. Talking about translators. people usually say: They must have known a foreign language well. That so. In the west, things are even worse. A translator's name cannot be displayed on the cover like the writer. And translation industry is much of a service one. Translators serve as an escort or a counselor. The truth is a translator is like an artist, a musician or an actor etc. Translation has its scientific and artistic sides.

Shakespeare said there were 1,000 Hamlets in 1,000 people's eyes. I would say for 1,000 translators there could be 1,000 Lin Daiyus. The views of this character are mixed. Translation is another type of writing. It calls for creativity. The act of translation is the reborn of a piece of works. The personality, academic background, and social level of all shape the soul of a translator.

\section{References}

[1] Andrew S. Editions and Translations, Approaches to Teaching the Story of the Stone. New York: The Modern Language Association of America, 2012.

[2] Baker M. Encyclopedia of Translation Studies. London and New York: Routledge, 1998.

[3] Bassnett S. Translation Studies. Shanghai: Shanghai Foreign Language Education Press, 2004.

[4] Nida E. Language, Culture and Translating. Shanghai: Shanghai Foreign Language Education Press, 1993.

[5] Venuti L. The Translator 's Invisibility: A History of Translation. Shanghai: Shanghai Foreign Language Education Press, 2004.

[6] Williams G. A Beginner's Guide to Doing Research in Translation Studies. Shanghai: Shanghai Foreign Language Education Press, 2004. 